\title{
THE RELATIONSHIP BETWEEN PLANNING AND THE PROSPECT OF URBAN REGENERATION: A PILOT PROJECT CALLED “A HOLISTIC STRATEGY FOR THE REGENERATION OF PERI-URBAN AREAS IN THE NORTH-WEST AREA OF ROME"
}

\author{
MARIA RITA SCHIRRU \\ Sapienza University of Rome, Italy
}

\begin{abstract}
This abstract will investigate the relationship between the tools employed in urban planning and integrated initiatives aimed at relaunching urban areas particularly affected by social and economic degradation or hardship, by promoting a streamlining of existing heritage, the recovery of the suburbs and the reuse of underused or decommissioned public spaces. The goal of this study is to understand whether - and if so, to what extent - urban renewal can become a key feature of urban planning tools, over and beyond the logic behind the dissemination of point interventions, encouraged by some sectorial, regional regulations but devoid of any strategic value within the substantially static urban legislative framework. Lazio regional law no. 7 in 2017 on urban renewal and building recovery reiterates, in fact, reward mechanisms enshrined in law but not, however, included in a planning framework decided upon by local councils, practically confirming the incentives already provided for by the "Housing Plan" (Piano Casa). Therefore, planning must once more play a central role in general, territorial development forecasts, by striking the right balance between growth and the sustainable renewal of cities. The case study chosen is part of an overall strategy for redevelopment and safety in the city outskirts - as stated in the invitation to tender approved in the 25 May 2016 government decree (DPCM, Decreto del Presidente del Consiglio dei Ministri) - and proposes an urban renewal project that begins with the enhancement of architectural features that resonate strongly in the memory of places (such as the Boccea and Triumphal Forts in the north-west area of Rome) in order to recover architectural value and to rejuvenate a degraded urban fabric. The expected results will confirm the potential of the pilot project to become the precursor for a strategic planning reorganization, aimed at urban renewal promoted by local administrations. The conclusions will refer to the ability of urban planning to absorb current experiences in the context of renewal and to convert them into a routine planning path.
\end{abstract}

Keywords: urban regeneration, routine planning, peri-urban planning.

\section{INTRODUCTION}

\subsection{From uprading to regeneration}

As highlighted by Couch et al. [1] urban regeneration policies and interventions in various European countries have taken place in different institutional and cultural contexts with specific socio-economic and environmental conditions. Despite the differences observed, a political and cultural debate has evolved, encouraging comparative studies and exchanges of experiences between different European countries, which has led to a significant merging of various fields of research around some areas on which to base effective policies for the regeneration of cities, including: the need for an integrated approach; reference to an "area based" model; reliance on "multi-stakeholder and multi-level" governance; an eye on environmental sustainability; and the struggle against climate change [2]. 
The integrated approach to the regeneration of cities combines economic, social and physical environment aspects and is based on the acknowledgement of the multidimensional nature of urban problems and the need to act holistically so that interventions undertaken to solve an individual problem consequently make solving other problems easier.

The area-based approach concerns the growing tendency of regeneration policies implemented in Europe to focus on specific areas where various problems overlap and where the challenges faced by transformation are greater.

Multi-stakeholder and multi-level governance foresee the setting-up of a network of crosscutting relationships that moves towards the building of a process of participation and consultation of all the public and private players involved.

Roberts and Sykes [3] in Urban Regeneration: A Handbook argue that urban regeneration is an emerging and innovative sector of urban planning policy that can be defined as a universal and integrated vision leading to the resolution of urban problems and aiming to improve the economic, physical, social and environmental conditions of the area being transformed.

Before urban regeneration, which first appeared in the vocabulary of English urban planning in the mid-1970s, urbanism was already familiar with the similar concept of urban renewal, established in England as a reaction to the poor hygienic conditions of its inhabitants during the Industrial Revolution in the 19th century. In France, after the cholera epidemic of 1849 , a law was introduced to regulate housing characteristics and to allow the expropriation of houses unfit for inhabitation - in Paris in 1852 the reconstruction of parts of the city was led by Haussmann. In Italy, Law 2359 in 1865 on expropriation for public use to rehabilitate cities was approved, followed by Law 2892 in 1885 on the building rehabilitation of Naples. In 1854, Ildelfons Cerdà published the theory of urbanisation and later in 1867 the general theory of urbanization. In 1889, Camillo Sitte published Der Städtebau nach seinen künstlerischen Grundsätzen (The Art of Building the City). Ebenezer Howard published Tomorrow, a peaceful path to real reform in 1898, which was reprinted in 1902 with the title Garden cities of tomorrow, with the aim of limiting the growth of cities in order to reduce overcrowding and improve building and health conditions [4].

Evans and Shaw [5] in their 2003 essay The contribution of culture to regeneration in the UK: a review of evidence, which further evolved the definition of urban regeneration in its English context, focused their attention on the link between building regeneration and cultural regeneration and on how the latter can become a true catalyst for urban regeneration policies. Moreover, in 2003, establishing a new definition, the British government stated that urban regeneration was not simply a question of bricks and mortar but that its ultimate aim should be the physical, social and economic well-being of the territory or, in other words, quality of life [6].

A confirmation of the evolution in the definition of "urban regeneration" can be found in French policy over the last ten years: in fact, the Nouveau programme de renovellement urbain 2014-2024 updates the goals and policies of the National Programme de rénovation urbaine (PNRU), launched in the previous decade, redesigning the standard goals framework and introducing a new method for intervention that places inhabitants at the heart of the process and takes better account of the social and economic aspects of urban policy, within the framework of new "city contracts".

The new guidelines envisage the focusing of interventions on the districts with the highest levels of urban dysfunction, the creation of a "project house" for each intervention so that inhabitants have access to a place dedicated to "co-construction", the involvement of residents in all the evolving phases of intervention (from design to evaluation, through to 
implementation) and the facilitation of sustainable renewal of urban areas and the improvement of energy efficiency, leading to the creation of eco-districts [7].

\subsection{Positive experiences of urban regeneration in the United Kingdom}

The United Kingdom, alongside France, can undoubtedly boast decades of experience in the field of urban regeneration, with particularly significant case studies [8].

We make particular reference here to the Northern Powerhouse plan for the economic revival of some cities in the north (Manchester, Liverpool, Leeds) which, after more than 20 years of regeneration work on individual cities, aims to establish a conurbation along the lines of the Rhineland and the Dutch Randstad, focusing in particular on transport infrastructure and the specific features of the city economies in question.

Another significant example is the experience of the Olympic Park in London, where the area destined for Olympic venues and facilities had already been included in London's regulatory plan as an area to regenerate long before London was awarded the Olympics and was therefore fully integrated into a strategic development framework for the UK capital, without modifications to the initial plan as often happens in our country. It should also be noted that the legacy of the Games was already detailed in the bidding process seven years beforehand as a key goal. Furthermore, a three-year plan was developed (and concluded in 2016) to create a residential and commercial urban district around Queen Elisabeth Olympic Park, which was opened to the public in 2013 as London's first new public park for over a century.

Worthy of note is also the urban regeneration of Salford Quays in old industrial Manchester, consisting of ninety hectares of docks and depots that supported the city's manufacturing sector. However, with the growth in container transport and the development of intermodal infrastructure, it gradually lost importance until it was abandoned in the early 1980s when the entire area was purchased by Salford Council (a crucial factor in subsequently controlling the regeneration process). Only in the 1990 s did the local administration decide to adopt a winning approach for the regeneration of the area, focusing on the driving effect of cultural and artistic events. In fact, the 1992 plan placed two strong cultural landmarks at the centre of the intervention work: the headquarters for the collection of paintings by Laurence S. Lowry and the Imperial War Museum North. Public commitment to these two projects has been a driving force for private investment which have since relaunched the area.

Finally, it is worthwhile highlighting intervention work on the site of Hadrian's Wall, the ancient Roman defensive structure that spans about 120 kilometres from the east to west coast of England, (crossing Cumbria and Northumberland) and declared a UNESCO World Heritage Site in 1987. As an intervention of urban regeneration applied to cultural heritage in the territory, it was prepared through a management plan in 1996 that involved various stakeholders, both landowners and public bodies with institutional duties and responsibilities. The plan has been revised several times and has led to the creation of strong partnerships as well as the adoption of a shared vision within communities, thanks to a holistic approach that does not consider the archaeological asset alone but all its relationships and ties with the territory. Among the results achieved, those worthy of mention are: the creation of a walking path and a cycle path that flank the wall along its entire length; the establishment of a bus service not only for tourists but also for no-car households; and other solutions to facilitate sustainable access to the site. The current management plan has a 30-year outlook and despite the closure in 2014 of the Hadrian's Wall Trust (set up specifically for this purpose), the 
transition to new management bodies (mainly but not exclusively English Heritage) has not affected the original goals.

\subsection{A comparison between Rome and London}

Policy in the UK highlights the importance of having well-defined and structured governance in order to address urban regeneration programmes effectively. One of the keys to success of the cases described above has in fact been the continuity in pursuing long-term programmes, albeit with a flexible approach, that can adapt to changing circumstances without distorting or abandoning primary objectives, can define objectives and structure intervention tools to draw consensus around the plans, can concentrate economic resources, and can engage all stakeholders, including ordinary citizens, in a long-term strategy [8].

We should not forget however that the success of English policies is due to the fact that they are the product of a very deep-rooted, consolidated strategic planning process where a multiplicity of players - public and private institutions, organizations and associations negotiate, adapt and merge in order to build consensus. It is a dynamic and interactive process that does not lead to an unbending and settled plan but to a flexible, non-binding policy document, which contains choices with a medium- to long-term outlook, within a constantly evolving process.

In fact, Anglo-Saxon countries boast a long tradition in strategic planning which can be traced back to the 1960s when in Great Britain framework plans were established over local territories, mainly with a socio-economic focus and a medium or long-term outlook. The Town and Country Planning Act in 1968 introduced the Structure Plan which would then evolve into Local Plans. Unlike previous developmental plans, it paid greater attention to economic and social problems.

Contents, methods and tools have since changed, leading to the definition of different generations of strategic plans: the "systemic" ones from the 1960s, like the Structure Plans (first generation); neo-utilitarian, business-derived plans from North American in the 1980s (second generation); and plans based on a transactional, networking and visionary model, with networks of mediation and negotiation between various players and the definition of "desirable scenarios", at a time when third sector organisations are beginning to emerge from the shadows and the need to protect the environment is becoming increasingly urgent (third generation) [9].

Rome, unlike other cities (particularly London), lacks a strategic plan but does have a structural plan that oversees significantly unchanged factors in the organisation of the city, to which widespread urban tissue renewal policies are attached, and dictates their rules and procedures. This allows local administrations (whose ultimate responsibility it is) to operate within a single framework, thus avoiding disparities arising from excessively autonomous decisions among the different boroughs within the same city.

London has essentially made its regeneration choices in accordance with this plan (take for example the case of the Olympic Games, where the locations for the Games were chosen from areas already earmarked by the regeneration plan) or through the preparation of a new ad hoc plan (as in the case of the plan to transform Manchester's industrial area for new cultural purposes). Rome, however, in some specific cases, must use an "urban variant" tool, as with the project for the new A. S. Roma football stadium in Tor di Valle. The interventions on the Forts (the subject of this paper) have been foreseen differently: "in variation" for the Triumphal Fort, through the Recovery Plan tool pursuant to Law 457/78, whilst the other (Boccea Fort) complies with the plan through the tool of local centrality. 
However, it should be noted that until now in Rome, thanks to the structural plan that aims to regenerate and modernise, the majority of urban transformation programmes (recovery programmes, urban regeneration programmes, integrated intervention programmes) were in fact included in the planning process, evolving from extraordinary to ordinary tools. This in contrast with other contexts where complex programmes under national legislation (taken back from regional legislation) were used as variation from the original plan. As indicated in Rome's 2003 General Regulatory Plan (PRG, Piano Regolatore Generale) report, renewal is wrong if it goes against the plan - these tools can represent, at least in essence, an operational apparatus to which urban reform refers when it defines the second component of the Regulatory Plan.

The relationship between urban regeneration programmes provided for by Regional Law no. 7/2017 on urban regeneration and existing planning remains to be understood. It is no coincidence that regional law for urban intervention provides for the involvement of municipalities in the identification of suitable territorial areas for the achievement of the end goals of urban regeneration.

Therefore, we must bear in mind how the boundaries of the areas destined for urban regeneration programmes is a political choice and part of a broader strategy of territorial government which includes: how regeneration programmes will be enclosed, structured and implemented; the changes/additions to the provisions of the Technical Implementing Rules and to the related PRG graphs; the necessary provisions so that, pending the updating of prescriptive and management tools and the revision of foreseen planning, utmost protection is provided to valuable urban fabric and the areas to be recovered.

\section{CURRENT PLANNING}

In February 2008, Rome Council approved its new general regulatory plan [10] which was the final phase of a process of progressive in-depth study of the founding principles of the planning framework that resulted from it (Fig. 1).

About ten years earlier, in 1997, the local administration had approved a somewhat revolutionary urban planning tool called the "Plan of Certainties": this tool did not, in fact, include regulations but held instead a vision developed in advance of a series of variants and adjustments that had made the current regulatory plan an incoherent set of forecasts, with some being general and others sector-specific (area plans, proposals for integrated programmes, urban recovery plans, etc.) [11].

The forecast framework that had been established was, in essence, an unresolved amalgamation of original features of the regulatory plan (designed by a team supervised by Luigi Piccinato) and the many opportunities offered over time by vibrant urban legislation, especially with regards urban regeneration and the defence of protected areas. This brought to completion a pathway that, since the early $1990 \mathrm{~s}$, had called on municipalities to respond both to the need to renew degraded areas in the territory and to the demands of key players and operators increasingly interested in using innovative, negotiation tools, very often excluded from the general urban planning tools currently in force [12].

It should be understood that, through the introduction of Law 241 in 1990, the State had begun to introduce a series of significant innovations regarding the relationships between citizens and institutions, with particular reference to the transparency of legal acts and documentation and an equal role in these relationships which aimed at facilitating the efficient transformation of the territory.

Firstly, Law 179 (1992) and subsequently Law 493 (1993) laid down a new negotiating pathway where local operators and administrations could finally liaise in terms of results, 


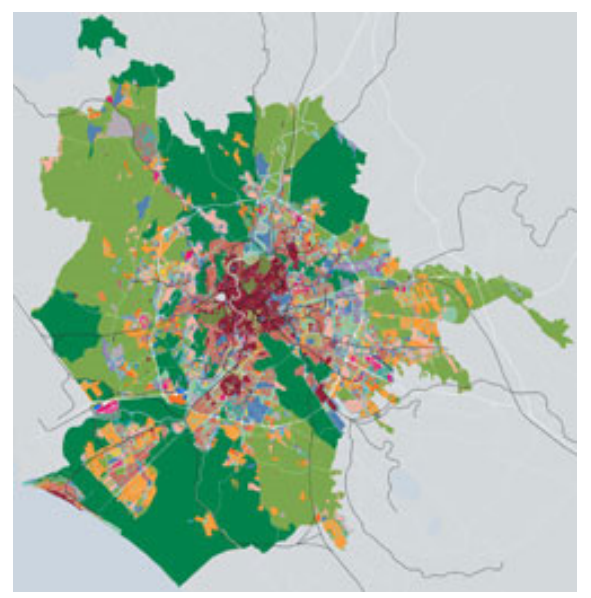

Figure 1: Rome's General Regulatory Plan.

based on reciprocal costs/benefits and no longer had to follow rigid legislation often made on the basis of irrelevant or unachievable forecasts.

In Rome, in particular, the emerging system of regulatory evolution was reflected in the need to re-evaluate intervention proposals within a complex framework made up of expansion, redevelopment, a protective overarching (regional or state) framework, and the linking up of parts of the territory that had been left highly degraded and lacking in any kind of organisation as a result of the growth in unplanned construction.

Building amnesties (three in less than twenty years) for illegal construction, thus legitimising "spontaneously" created building volumes, have paradoxically put together sets of buildings that have however some territorial importance.

In 1997, Rome's local administration felt the need to reassess the PRG (Piano Regolatore Generale) which is now only formally in force - and thus approved the addition of the aforementioned "certainties" which, in reality, rather than planning for the future, incorporated into a single administrative tool what had already taken place in the territory that had made it impossible to adhere to the original forecasts.

The importance of this measure lies in its ability to reorganise the territory, meant as a rebalancing process between protected parts of the city and those lacking initial building capacity: as a result, the "compensation" tool was established.

"Compensation", subsequently laid out in the 2008 PRG, represents an essential opportunity for territorial rebalancing, aimed at the redistribution of building forecasts, between areas and key players/operators, in accordance with the principles of equity and compliance and taking into account previous urban planning regulations, legitimate existing buildings, and the pursuit of the public interest.

The goals of forecasting fairer distribution are achievable through specific urban and financial equalization (or smoothing) cases, both by identifying territorial compensation areas and economic and administrative tools.

It should be noted that the implementation rules contain the seeds of the regulatory and cultural evolution in the principles of urban regeneration that, after almost ten years of animated debate on the subject, led the Lazio Region to issue a specific legislative measure (Law No. 7, 2017) [13]. 
In fact, the proposals for urban transformation carried out through this instrument of compensation explicitly provide that part of the additional building land is made available for the purposes of public interest, such as social housing, environmental protection, urban renewal and the explicit laying out of incentives for interventions for the renewal of degraded building stock in so-called compensation areas.

The above should make us reflect on the path that has run through the debate on urban regeneration over the last twenty years, intended not merely as a question of forecasting and building as an alternative to expansion criteria, but as a legislative and cultural issue aimed at limiting land use and at simultaneously identifying interventions in degraded areas in the urban fabric.

This development shifts the nature of intervention on heritage from building replacement to urban regeneration, with a qualitative leap that is not merely semantic but implies the scientific-academic redefinition of the problem and its resetting in terms of implementation. The implementation legislation in the PRG on this issue acknowledges, therefore, two fundamental criteria:

- Building forecasts that can be exercised in situ or transferred to other areas attributed to the owners (i.e. the municipality) according to the criteria of fair distribution on the basis of forecasts which failed because of regulatory intervention or environmental and/or urban protection requirements;

- The provision of incentives for the renovation of degraded buildings on the basis of negotiation programmes, i.e. in accordance with the competition procedures decided upon by the administration itself.

Another important innovation included in the current PRG refers to the "reading" or interpretation of the territory aimed not at "zoning" but rather the subject of transformation activities compatible with the quality and features of the urban fabric where the general settlement system is shared.

The partition of municipal territory into regular areas (defined for the settlement system as areas for physical and functional alterations of urban importance) introduces a highly innovative concept in terms of intervention in the city.

The traditional distinction between consolidated and expanding cities is overturned in favour of a more appropriate division of the territory into areas of urban fabric, which no longer reflects the generic distinction between "centre" and "outskirts".

\section{FROM EXPANSION TO REGENERATION}

Reading (or interpreting) the territory as "fabric" and not merely as parts of the city (i.e. historical, consolidated and destined for expansion), typical of municipal planning until the mid-1990s and a direct consequence of the 1942 urban law, allows us to create a more suitable tool to represent territory needs. Specifically, we are dealing with a territory which has been seriously affected by phenomena of widespread development (the obvious consequence of spontaneous growth), a lack of coordination with interventions in derogation and formal legitimisation (the main outcome from the various building amnesties over the last thirty years).

The resulting framework, further enriched by the opportunities for transformation (timely rather than widespread and often focusing on delicate parts of the city) offered by the Housing Plan (Piano Casa), makes the Lazio Regional Law on urban regeneration an opportunity to reassess the territory in light of new regulations and to verify whether (and if so, how) the 
law can become a definitive (and not occasional) intervention tool in outskirts that often lack urban and architectural quality.

Analysing the detail of the legislative structure of the law, we note how the possibility of intervening on the existing one directly (and here the interpretation in the new PRG of Rome as areas of urban fabric is useful) is reflected in the provision of interventions on a much larger urban scale, after the creation of suitable "urban regeneration programmes" (art. 2) to be implemented with the procedures of the integrated intervention programme (also as a variant on the PRG).

The first four articles, in actual fact, define a forecasting structure which aims to involve municipalities in the goals of requalification and recovery by identifying, through city council resolutions, "urban territorial areas" which will host regeneration proposals.

Article 4 of the law also aims to involve municipal administrations by including in the general urban planning tool (through resolutions by the municipal council) the eligibility of intervention for individual building renovation up to a maximum surface area of 10,000 square metres.

It is clearly a complex forecasting framework which aims to facilitate intervention on existing buildings, in consideration of the fact that Rome Council, due to its territorial size and administrative complexity, would have significant problems in creating an overall framework of modifications to the general urban planning tool without carefully recognising its importance and the current state of implementation ten years after its approval.

One hopes that the law's primary action on urban regeneration will be directed towards the vast breadth of the proposals and not towards what has already been experienced with the Housing Plan, which has led to the development of interventions aimed more at building replacement (and therefore at increasing land income) rather than at a more useful general upgrading project on the wider territory, as was originally proposed.

\section{TWO EXAMPLES OF PILOT PROJECTS IN ROME}

The abstract at the beginning of this paper indicated the subject of the relationship between urban planning tools and integrated actions which aim to relaunch urban areas suffering hardship or social and economic degradation. The discussion of this issue highlighted the value of streamlining existing assets, renewing suburbs and reusing underused or abandoned public spaces.

It is therefore relevant to examine two proposals promoted by Rome Council in the context of the protocol agreement between the Ministry of Defence, Roma Capitale and the State Property Agency for the "streamlining and enhancement" of buildings in the capital [14].

Specifically, the Triumphal Fort [15] and the Boccea Fort [16] (Figs 2 and 3) were taken into consideration, both located in the north-west quadrant of Rome and both affected by heavy traffic congestion and high population density.

Given the title of this paper and based on the value of a holistic approach for the regeneration of the peri-urban areas in the north-west of Rome (assumed also to be cultural and academic), the first act was to verify the urban and morphological structure of the area of intervention and its relationship with the city.

What clearly emerges is the absence of a peri-urban outlook in the designated intervention area. Its other features are, however, appreciated, like the choice of a territorial area in the consolidated city, confirmed also by the urban planning target of "a defined 20th century expanding urban fabric with average levels of settlement density". This is the "small apartment block" (or palazzine) type of urban fabric, typical of the expansion in Roman construction that took place after the war and during the economic boom. 


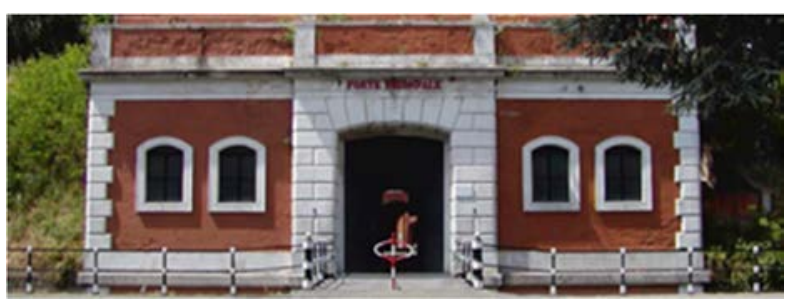

Figure 2: The Triumphal Fort in Rome.

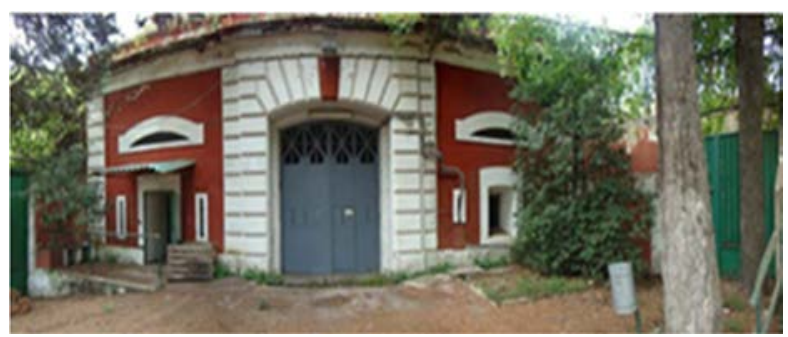

Figure 3: The Boccea Fort in Rome.

The presence of a road network with high levels of inter-district flow makes the area a separated nucleus from the wider urban context, with its own sense of belonging to the collective memory because of the strong identity of the places it hosts (historical, military forts, morphological features spread throughout the entire territory of the capital city).

These two strong morphological and urban features form the basis of the goals that Rome Council wants to achieve, and its choice to use the term "the fort belt" for regeneration projects in various parts of the city:

- To recover and enhance traces of urban morphology, as well as one of its historical principles of settlement characterising a particular period;

- Another aim is to strengthen local identity specific to each context in the area around the individual artefacts with a view to enhancing their main cultural functions;

- A further goal is to contribute to improving environmental networks, their ecological aspects and the strengthening of sustainable mobility.

From this perspective, Rome Council has identified the Triumphal Fort as a public service "hub", accessible also to the rest of the city and capable of positively affecting "lines of penetration" towards the centre, thus draining the flow.

The tool identified for the achievement of these goals is the recovery plan pursuant to Articles 27 and 28 of Law 457/78, to be implemented in “... areas that may include individual buildings, building complexes, blocks and areas, as well as buildings to be used for equipment".

In order to balance intervention against related costs, activities aimed both at the enhancement and "re-booting" of historic buildings and others aimed at private sector players/operators have been planned, with the provision of transferable land plots for residential use. 
In summary, the general criteria for the creation of the recovery plan can be described as follows:

- Conservation restoration of the Fort with the addition of new public functions compatible with its morphological features;

- New residential, commercial and service buildings compatible with the features of its urban fabric;

- Reorganisation of public and private open spaces and an increase in service provisions and local public spaces;

- The realisation of an architectural project based on research and quality and high levels of energy self-sufficiency.

The second case in question is the enhancement of Boccea Fort, described as "the Boccea regeneration hub".

As in the previous case, the size and shape of the area of intervention are strongly affected by pre-existing building: the fort, in fact, with its aesthetic and functional features, is highly recognisable from a morphological perspective and influences the urban context where it is located, helping to establish the collective memory of these places.

Unlike the Triumphal Fort, the intervention on the Boccea Fort highlights a different set of goals to be achieved, because of both the differing identity of the urban and socioeconomic context and the relationship with the PRG forecasts. We are, in fact, in an area adjacent to a local centre, i.e. a hub with a suitable structure for PRG implementation.

Its high population density and the presence of infrastructure for significant inter-district flow has led to a forecast aimed at providing the district with new facilities and services at a local level, to be achieved through the relocation of the Urban II District Market.

In particular, the intervention also aims to overcome the consolidated model of the local market (fixed hours, limited product range, precarious structures, etc.) and to move instead towards innovative models, including also mobile stalls.

The endeavour is to build something new at the disposal of the neighbourhood that can accommodate new community demands and establish a new relationship with the city, reinterpreted in light of the changes introduced by the general urban planning tool.

From an implementational point of view, the use of a different urban planning tool for goal achievement comes to the fore immediately: a recovery plan with significant negotiation tools to employ with private entities interested in playing a role with regards the Triumphal Fort; a project that complies with the plan through the tool of local centrality for Boccea Fort.

\section{CONCLUSIONS}

As mentioned above, the Lazio Region law on urban regeneration, in its role as an operational tool in the urban area of Rome, has acquired new and different meanings, both because of the opportunity to intervene in wide ranging, well-structured situations and the "comparison" with the provisions of a general urban planning tool capable of "reading" urban fabric in a timely fashion and of classifying them according to their specific features.

It should be noted, however, that its legislative scope, whilst not providing modifications to current urban planning instruments in force, involves implementation procedures governed by resolutions made by the local council that allow us to bring consistency to the opportunities foreseen by the law and the principles of territorial planning (the responsibility of local governments).

Looking closely at the regional law, we see that it provides a general framework of very well-structured legislation including the provision of implementation through integrated 
programmes of intervention in urban areas, the identification of urban areas where redevelopment interventions can be made on existing building stock, and the provision of interventions to be directly implemented with a premium increase in volume in accordance with the PRG.

What emerges clearly from the comparison with regional law is the subject of the relationship between superordinate measures and guidelines that each municipality sets itself for developing its territory.

In fact, the opportunity for local administrations to act by identifying areas to locate the activities provided for by regional law implies the contextual need to both introduce procedures to ascertain the actual status of implementation of the plan and to respond to changing market conditions and socio-economic conditions in urban contexts.

The lasting effects of the construction sector crisis, following the decade-old economic situation, mean the forecasts of the PRG - albeit formulated on the basis of an accurate and timely identification of urban conditions - deserve a thorough examination of its compatibility with the various changing demands of the territory and society in terms of housing needs and sustainable building development.

For this reason, it would appear appropriate to limit opportunities to transform established urban fabric, where the impact of the new cannot be allowed to compromise the idea of improving urban and building quality, including historical parts of the city and the historical urban fabric.

We have recently seen how a casual use of the opportunities included in the Housing Plan has produced critical situations through interventions in urban areas with inherent and consolidated qualities - albeit in the absence of specific binding measures - with a resulting loss of identity and collective memory of places as well as a negative impact on existing socio-economic realities.

For this reason, the interventions on military forts studied here move towards a correct approach to the subject of transformation of urban areas that are degraded, underused or detached from their contexts. These programmes of intervention are promoted by the municipal administration as part of a broader strategy of initiatives aimed at re-booting public areas that can result in an improvement in urban quality and an active interest on the part of various operators in the sector.

\section{REFERENCES}

[1] Couch, C., Sykes, O. \& Borstinghaus, W., Thirty years of urban regeneration in Britain, Germany and France: The importance of context and path dependency. Progress in Planning, 75, pp. 1-52, 2011. DOI: 10.1016/j.progress.2010.12.001.

[2] Talia, M. \& D’Onofrio, R., La rigenerazione urbana alla prova, Franco Angeli: Milano, 2015.

[3] Roberts, P. \& Sykes, H., Urban Regeneration: A Handbook, SAGE: Los Angeles, London, New Delhi, Singapore, Washington DC, 2008.

[4] Carpentieri, P., Dalla resilienza alla rigenerazione. La politica industriale per il lavoro utile, Arianna Editrice: Bologna, 2013.

[5] Evans, G. \& Shaw, P., The Contribution of Culture to Regeneration in the UK: A report to the DCMS, LondonMet, 2004. Online. www.scholars-on-bilbao.info/fichas/ EvansShaw2004.pdf. Accessed on: 15 Apr., 2018.

[6] Office of the Deputy Prime Minister (ODPM), Assessing the impacts of spatial interventions. regeneration, renewal and regional development. Main Guidance, London, 2003. Online. https://assets.publishing.service.gov.uk/government/uploads/ 
system/uploads/attachment_data/file/191509/Regeneration__renewal_and_regional_ deveopment.pdf. Accessed on: 15 Apr. 2018.

[7] Bellicini, L., Rigenerazione Urbana Sostenibile, 2015. Online. www.treccani.it/enciclopedia/rigenerazione-urbana-sostenibile_\%28EnciclopediaItaliana\%29/. Accessed on: 20 Apr. 2018.

[8] Pietrangeli, G., Rigenerazione. Fattori di successo dell'esperienza Britannica, 2017. Online. www.civiltadicantiere.it/articles/154. Accessed on: 15 Apr. 2018.

[9] Gibelli, M.C. \& Curti, F., Pianificazione strategica e gestione dello sviluppo urbano, ALINEA: Firenze, 1996.

[10] Comune di Roma, Piano Regolatore Generale. Norme Tecniche di Attuazione, 2008.

[11] Comune di Roma, Ufficio Nuovo Piano regolatore Piano delle Certezze, Allegato «a»: variazione delle norme tecniche di attuazione del PRG, 2004.

[12] Comune di Roma, Piano Regolatore Generale del Comune di Roma. Relazione e norme tecniche per l'attuazione del piano, 1965.

[13] Regione Lazio, Legge Regionale n.7 del 18 luglio 2017 "Disposizioni per la rigenerazione urbana e per il recupero edilizio". Online. www.consiglio.regione.lazio.it/binary/consiglio_regionale/tbl_pubblicazioni/adempi menti_1.r._7_2017.pdf. Accessed on: 2 Mar. 2018.

[14] Comune di Roma, Deliberazione di Giunta Capitolina n. 30 del 25 agosto 2016. Bando per la presentazione di progetti per la predisposizione, da parte della Città Metropolitana di Roma Capitale, del "Programma straordinario di intervento per la riqualificazione urbana e la sicurezza delle periferie delle città metropolitane e dei comuni capoluogo di provincia." Online. www.romainpiazza.it/wpcontent/uploads/2016/09/DGCDelib.-29e30-del-25.08.2016-Roma.pdf. Accessed on: 2 Mar. 2018.

[15] Comune di Roma, Una Strategia olistica per la rigenerazione delle aree periurbane del quadrante nord-ovest di Roma. Intervento 01-"Polo di rigenerazione del Forte Trionfale," 2015a.

[16] Comune di Roma, Una Strategia olistica per la rigenerazione delle aree periurbane del quadrante nord-ovest di Roma. Intervento 02-"Polo di rigenerazione del Forte Boccea, 2015b. 